\title{
Alokasi Biaya dari Induk Perusahaan ke Anak Perusahaan PT. Pupuk Indonesia (Persero)
}

\author{
Surtikanti $1^{*}$ \\ 1 Program Studi Akuntansi, Fakultas Ekonomi dan Bisnis, Universitas Komputer Indonesia, \\ Jl. Dipati ukur No.112-118, Bandung, Indonesia. \\ Corresponding Email: surtikanti@email.unikom.ac.id 1.
}

\section{Article History:}

Received: Jul 17th 2021

Revised: Aug 4th 2021

Accepted: Aug 16th 2021

Keywords: Cost Allocation

Rates; Fixed Cost; Variable

Cost; Parent Entity;

Subsidiary Entity.
Abstract: The purpose of this activity is for the basis of reference for the parent entity and subsidiaries engaged in the fertilizer and non-fertilizer industries in setting the allocation of marketing, procurement, and information technology costs appropriately. The method of implementation of devotional activities consists of classical and discussion by means of webinars. Based on the results of the activity can be seen: Allocation of costs from the Parent Entity to the Subsidiaries, in the marketing cost compartment by direct cost method, the cost allocation rate uses fixed costs and variable costs. The cost of this fee depends on the cost allocation basis. If the allocation basis is valid for 1 year and will be set annually, then the cost allocation rate uses a fixed rate, which is the amount of the allocation proportional to the sales RKAP. While the basis of allocation is fixed every period following the activities of subsidiaries, the allocation of tariffs using variable tariffs, which is a large allocation proportional to the value of sales realization. 


\section{Pendahuluan}

Seiring dengan dinamika dan perubahan lingkungan bisnis, perkembangan perusahaan dapat dilihat dari perubahan dan penambahan Anak Perusahaan. Pembentukan dan keberadaan Anak Perusahaan merupakan keputusan strategis yang ditujukan dalam rangka penciptaan sinergi dan nilai tambah bagi grup secara keseluruhan. Di satu sisi, peningkatan pertumbuhan dan kinerja Anak Perusahaan akan berdampak pada peningkatan kinerja Induk Perusahaan melalui konsolidasi laporan keuangan, sementara pada sisi yang lain Anak Perusahaan akan mengalami peningkatan kinerja dan pertumbuhan bisnis melalui dukungan pengelolaan dan bisnis yang diberikan oleh Induk Perusahaan. Melalui hubungan sinergis dan bernilai tambah tersebut, induk dan Anak Perusahaan akan mengalami peningkatan kinerja, ketahanan bisnis dan operasional, serta keunggulan daya saing grup secara berkelanjutan $[1,2,3]$.

Keberadaan PT Pupuk Indonesia (Persero) yang merupakan sebuah kelompok usaha (Holding Company) ditetapkan melalui Peraturan Pemerintah Nomor 28 Tahun 1997 tentang Penambahan Penyertaan Modal Negara Republik Indonesia ke dalam Modal Saham Perusahaan (Persero) PT Pupuk Indonesia, yang pada saat itu masih bernama PT Pupuk Sriwidjaja (Persero), dalam bentuk kepemilikan saham Pemerintah pada Perusahaan berikut: PT Pupuk Kalimantan Timur, PT Petrokimia Gresik, PT Pupuk Kujang dan PT Pupuk Iskandar Muda. Selain keempat perusahaan tersebut, PT Pupuk Indonesia (Persero) juga merupakan pemilik saham PT Mega Eltra berdasarkan Peraturan Pemerintah Nomor 34 Tahun 1998 tentang Penambahan Penyertaan Modal Negara Republik Indonesia ke dalam Modal Saham Perusahaan (Persero) PT Pupuk Sriwidjaja, serta PT Pupuk Indonesia (Persero) juga memiliki penyertaan modal di PT Rekayasa Industri, PT Pupuk Indonesia Logistik, PT Pupuk Indonesia Energi dan PT Pupuk Indonesia Pangan sebagai Anak Perusahaan [4].

Adanya perubahan bentuk perusahaan yang awalnya merupakan perusahaan sendiri sekarang berada dibawah satu kendali yaitu induk perusahaan (Holding Company). Hal ini menyebabkan proses bisnis mengalami perubahan adanya pengambilalihan dalam pengelolaan beberapa fungsi perusahaan. Sehingga Pupuk Indonesia harus membuat suatu Pusat biaya yang berhubungan dengan kegiatan penentuan kebijakan, pengarahan, dan pengawasan kegiatan perusahaan secara keseluruhan agar dapat berhasil guna (efektif) dan berdaya guna (efisien) [5,6]. Kriteria yang dapat digunakan dalam pedoman alokasi biaya $[7,8]$ :

1) Sebab Akibat

Berdasarkan kriteria ini manajemen mengidentifikasikan variabel-variabel yang menyebabkan penggunaan sumber-sumber seperti pengelolaan sumber daya barang, jasa dan SDM.

2) Manfaat Yang Diterima

Berdasarkan kriteria ini manajemen mengidentifikasikan biaya yang dialokasikan 


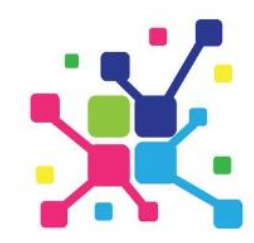

berdasarkan manfaat yang diterima masing-masing unit kerja.

3) Keadilan Atau Kewajaran

Kriteria ini biasanya memperhatikan keterkaitan kesepakatan (kontrak) dengan alokasi biaya untuk penetapan harga menjadi wajar.

4) Kemampuan Memikul Biaya

Kriteria ini menyarankan agar alokasi biaya dilakukan secara proporsional dengan kemampuan dari objek biaya untuk memicu biaya yang dialokasikannya.

Agar Pupuk Indonesia dapat mengalokasi biaya-biaya yang telah dikeluarkan Pupuk Indonsia kepada anak perusahaan dalam menjalankan fungsi anak perusahaan dan adanya pembagian yang merata antara anak perusahaan, maka Pupuk Indonesia harus membuat penetapan pedoman alokasi biaya usaha Pupuk Indonesia dari induk perusahaan ke anak perusahaan sia dengan anak-anak perusahannya sendiri.

Berdasarkan masalah di atas penulis berupaya untuk memberikan sedikit kontribusi berdasarkan teori dan praktek yang sudah dilakukan dengan melakukan kajian penetapan pedoman alokasi biaya dari induk perusahaan ke anak perusahaan. Tujuan dari kegiatan ini adalah untuk dasar rujukan bagi entitas induk dan entitas anak yang bergerak di industri pupuk dan non pupuk dalam menetapkan alokasi biaya pemasaran, pengadaan dan teknologi informasi secara tepat. Agar terciptanya efisiensi biaya pemasaran, pengadaan dan tehnologi informasi pada entitas anak dan terciptanya efektifitas kegiatan pemasaran, pengadaan dan tehnologi informasi pada entitas anak Manfaat yang diharapkan memberi solusi terutama bagi Anak Perusahaan dan Induk Perusahaan dalam menangani biaya yang dialokasikan dari Induk Perusahaan ke Anak perusahaan.

\section{Metode}

a. Metode Pelaksanaan Kegiatan

Metode pelaksanaan kegiatan pengabdian terdiri dari klasikal dan diskusi dengan cara webinar yang meliputi beberapa tahapan yaitu; 1 ) Identifikasi unit bisnis masingmasing anak perusahaan, 2) Menginput data biaya anak perusahaan Pupuk Indonesia, 3) Mengidentifikasi mana pendapatan dan biaya anak-anak perusahaan yang akan dialokasi, 4) Membuat alokasi biaya ke anak-anak perusahaan, 5) Mengkonfirmasikan selisih diantara pendapatan tersebut, dan 6) Menyusun draft laporan akhir kegiatan pengabdian kepada masyarakat ini.

b. Waktu Efektif Pelaksanaan Kegiatan

Pelaksanaan Pengabdian Kepada Masyarakat ini dilakukan pada 15 Maret 2021 sampai dengan 30 Juni 2021.

c. Tempat Kegiatan

Lokasi pengabdian ini dilaksanakan pada PT. Tritech Consult Indonesia. 


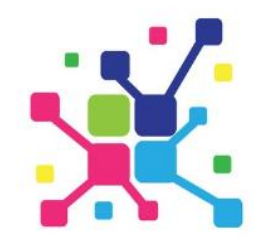

A J A D

Jurnal Pengabdian kepada Masyarakat

Vol. 1, No. 2, October, 2021, pp. 45-53 DOI : https://doi.org/10.35870/ajad.v1i2.12

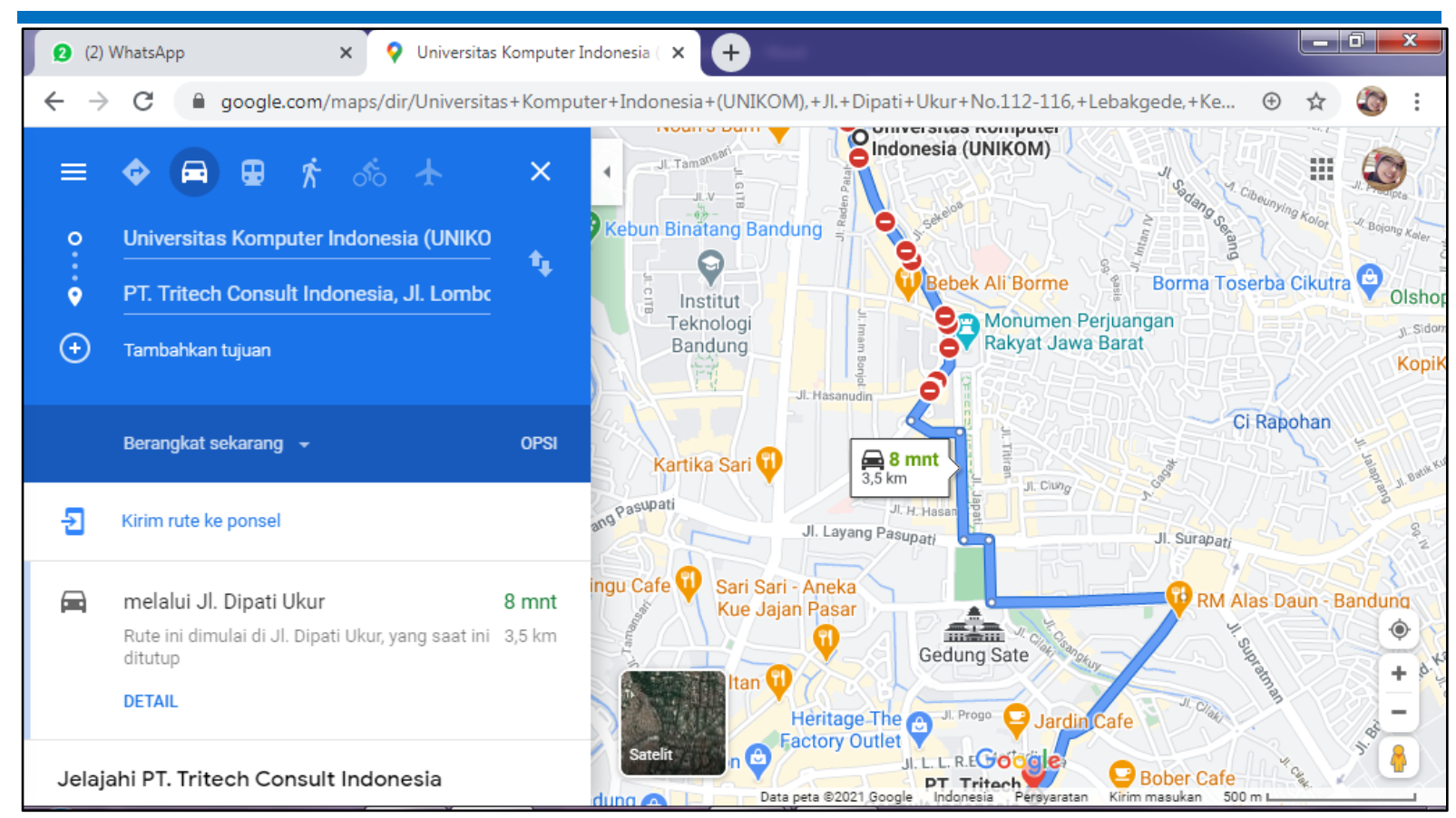

Gambar 1. Map Lokasi Kegiatan

\section{Hasil}

Sejak terdapat masalah pandemi yang terjadi di seluruh negara maka untuk menghindari penyebaran covid, setiap aktivitas di usahakan melalui online (daring). Pembahasan hasil pkm ini dilakukan dengan diskusi secara online.

\section{Proses Alokasi dari Entitas Induk ke Entitas Anak}

1. Menentukan Pusat Biaya yang Dialokasi

2. Menentukan Metode Alokasi Biaya

3. Menentukan Komponen Biaya yang Dialokasi

4. Menentukan Dasar Alokasi

a) Fungsi Pemasaran yaitu Kwantitas Penjualan Realisasi, Nilai Realisai Penjualan, Nilai Penjualan dalam RKAP.

b) Fungsi Pengadaan yaitu Nilai realisasi purchase order dan RKAP Purchase Order

c) Fungsi Teknologi Informasi yaitu Jumlah User ID dan Nilai Intangible Asset Sistem SAP.

5. Menentukan Tarif Alokasi

Terdapat dua pilihan tarif alokasi yaitu tarif tetap dan tarif variabel. Kriteria dalam penentuan tarif alokasi untuk setiap fungsi terdiri dari: [4]

a) Pusat biaya yang menggunakan tarif tetap adalah yang memiliki fungsi perencanaan dalam uraian tugas.

b) Pusat biaya yang menggunakan tarif variabel adalah yang memiliki fungsi gabungan, yaitu perencanaan, koordinasi dan pengendalian. 
Dalam menentukan tarif alokasi biaya ada dua pilihan $[9,10]$

1) Tarif Tetap

Tarif tetap setahun

Tarif ini berlaku untuk 1 tahun berjalan dan akan ditetapkan setiap tahun.

Tabel 1. Contoh Alikasi Biaya Menggunakan Tarif tetap

Contoh alokasi biaya menggunakan tarif tetap

\begin{tabular}{|l|c|c|c|c|c|c|}
\hline \multicolumn{1}{|c|}{ Katerangan } & PKG & \multicolumn{1}{c|}{ PKT } & \multicolumn{1}{c|}{ PKC } & \multicolumn{1}{c|}{ PIM } & \multicolumn{1}{c|}{ PSP } & \multicolumn{1}{c|}{ Total } \\
\hline RKAP Penjualan 2020 & 800.000 & 400.000 & 600.000 & 200.000 & 450.000 & 2.450 .000 \\
\hline Biaya SEVP Marketing 0p. Jan 2020 & & & & & & \\
\hline - Biaya Kas & & & & & & 400.000 \\
\hline - Biaya Non Kas & & & & & & 50.000 \\
\hline & & & & & & 450.000 \\
\hline & & & & & & \\
\hline Tarif Tetap & $33 \%$ & $16 \%$ & $24 \%$ & $8 \%$ & $18 \%$ & $100 \%$ \\
\hline Alokasi pusat biaya SEVP & & & & & & \\
\hline - Biaya Kas & 130.612 & 65.306 & 97.959 & 32.653 & 73.469 & 400.000 \\
\hline - Biaya Non Kas & 16.327 & 8.163 & 12.245 & 4.082 & 9.184 & 50.000 \\
\hline & 146.939 & 73.469 & 110.204 & 36.735 & 82.653 & 450.000 \\
\hline
\end{tabular}

2) Tarif variabel

Tarif yang ditetapkan setiap periode mengikuti aktivitas entitas anak. Besar alokasi proporsional dengan nilai realisasi.

Tabel 2. Contoh Alokasi Biaya Menggunakan Tarif Variabel

Contoh alokasi biaya menggunakan tarif variabel

\begin{tabular}{|l|c|c|c|c|c|r|}
\hline \multicolumn{1}{|c|}{ Katerangan } & PKG & \multicolumn{1}{c|}{ PKT } & \multicolumn{1}{c|}{ PKC } & \multicolumn{1}{c|}{ PIM } & \multicolumn{1}{c|}{ PSP } & \multicolumn{1}{c|}{ Total } \\
\hline Realisasi Penjualan Jan 2020 & 400.000 & 300.000 & 200.000 & 50.000 & 100.000 & 1.050 .000 \\
\hline Biaya SVP Strategic Marketing Triwulan 1 2020 & & & & & & \\
\hline - Total Biaya & & & & & & 200 \\
\hline & & & & & & 200 \\
\hline & & & & & & \\
\hline Tarif Variabel & $38 \%$ & $29 \%$ & $19 \%$ & $5 \%$ & $10 \%$ & $100 \%$ \\
\hline Alokasi pusat biaya SEPV & & & & & & \\
\hline - Total Biaya & 76,19 & 57,14 & 38,10 & 9,52 & 19,05 & 200 \\
\hline Jumlah Bulan Januari & 76,19 & 57,14 & 38,10 & 9,52 & 19,05 & 200 \\
\hline
\end{tabular}


Jurnal Pengabdian kepada Masyarakat

Vol. 1, No. 2, October, 2021, pp. 45-53

DOI : https://doi.org/10.35870/ajad.v1i2.12

Contoh alokasi biaya menggunakan tarif variabel Setelah reviu 1 Tahun

\begin{tabular}{|l|r|r|r|r|r|r|}
\hline Bulan & \multicolumn{1}{|c|}{ PKG } & \multicolumn{1}{|c|}{ PKT } & \multicolumn{1}{|c|}{ PKC } & \multicolumn{1}{c|}{ PIM } & \multicolumn{1}{c|}{ PSP } & Jumlah Biaya \\
\hline Januari & $38 \%$ & $29 \%$ & $19 \%$ & $5 \%$ & $10 \%$ & 50.000 \\
\hline Alokasi & 19.048 & 14.286 & 9.524 & 2.381 & 4.762 & 50.000 \\
\hline Februari & $26 \%$ & $35 \%$ & $17 \%$ & $4 \%$ & $17 \%$ & 10.000 \\
\hline Alokasi & 2.609 & 3.478 & 1.739 & 435 & 1.739 & 10.000 \\
\hline Maret & $29 \%$ & $25 \%$ & $25 \%$ & $6 \%$ & $15 \%$ & 25.000 \\
\hline Alokasi & 7.250 & 6.250 & 6.250 & 1.500 & 3.750 & 25.000 \\
\hline April & $30 \%$ & $26 \%$ & $24 \%$ & $7 \%$ & $13 \%$ & 20.000 \\
\hline Alokasi & 6.000 & 5.200 & 4.800 & 1.400 & 2.600 & 20.000 \\
\hline Mei & $31 \%$ & $24 \%$ & $23 \%$ & $10 \%$ & $12 \%$ & 30.000 \\
\hline Alokasi & 9.300 & 7.200 & 6.900 & 3.000 & 3.600 & 30.000 \\
\hline Juni & $35 \%$ & $29 \%$ & $17 \%$ & $8 \%$ & $11 \%$ & 35.000 \\
\hline Alokasi & 12.250 & 10.150 & 5.950 & 2.800 & 3.850 & 35.000 \\
\hline Juli & $32 \%$ & $25 \%$ & $20 \%$ & $9 \%$ & $14 \%$ & 37.500 \\
\hline Alokasi & 12.000 & 9.375 & 7.500 & 3.375 & 5.250 & 37.500 \\
\hline Agustus & $30 \%$ & $27 \%$ & $25 \%$ & $6 \%$ & $12 \%$ & 40.000 \\
\hline Alokasi & 12.000 & 10.800 & 10.000 & 2.400 & 4.800 & 40.000 \\
\hline September & $31 \%$ & $27 \%$ & $28 \%$ & $4 \%$ & $10 \%$ & 30.000 \\
\hline Alokasi & 9.300 & 8.100 & 8.400 & 1.200 & 3.000 & 30.000 \\
\hline Oktober & $28 \%$ & $29 \%$ & $23 \%$ & $5 \%$ & $15 \%$ & 35.000 \\
\hline Alokasi & 9.800 & 10.150 & 8.050 & 1.750 & 5.250 & 35.000 \\
\hline November & $30 \%$ & $31 \%$ & $20 \%$ & $5 \%$ & $14 \%$ & 40.000 \\
\hline Alokasi & 12.000 & 12.400 & 8.000 & 2.000 & 5.600 & 40.000 \\
\hline Desember & $30 \%$ & $29 \%$ & $22 \%$ & $7 \%$ & $12 \%$ & 50.000 \\
\hline Alokasi & 15.000 & 14.500 & 11.000 & 3.500 & 6.000 & 50.000 \\
\hline Tarif Alokasi Setelah Perhitungan Ulang & $\mathbf{3 1 \%}$ & $\mathbf{2 8 \%}$ & $\mathbf{2 2 \%}$ & $\mathbf{6 \%}$ & $\mathbf{1 3 \%}$ & $\mathbf{4 0 2 . 5 0 0}$ \\
\hline Alokasi Setelah Perhitungan Ulang & $\mathbf{1 2 4 . 1 6 5}$ & $\mathbf{1 1 2 . 4 8 3}$ & $\mathbf{8 8 . 3 6 2}$ & $\mathbf{2 5 . 5 2 8}$ & $\mathbf{5 1 . 9 6 1}$ & $\mathbf{4 0 2 . 5 0 0}$ \\
\hline Alokasi Sebelum Perhitungan Ulang & $\mathbf{1 2 6 . 5 5 6}$ & $\mathbf{1 1 1 . 8 8 9}$ & $\mathbf{8 8 . 1 1 3}$ & $\mathbf{2 5 . 7 4 1}$ & $\mathbf{5 0 . 2 0 1}$ & $\mathbf{4 0 2 . 5 0 0}$ \\
\hline Kenaikan (Penurunan) Setelah Perhitungan Ulang & $\mathbf{2 . 3 9 1 )}$ & $\mathbf{5 9 4}$ & $\mathbf{2 4 9}$ & $\mathbf{2 1 2})$ & $\mathbf{1 . 7 6 0}$ & \\
\hline
\end{tabular}

\section{Periode Alokasi}

\section{a) Periode alokasi tarif tetap}

Periode alokasi tarif tetap dapat dilakukan setiap bulan pada periode berjalan mengikuti periode laporan keuangan interim Entitas Anak.

\section{b) Periode alokasi tarif variabel}

Periode alokasi tarif variabel dapat dilakukan setiap bulan pada periode berjalan mengikuti periode laporan keuangan interim Entitas Anak dan dilakukan review kembali sebelum laporan keuangan terbit 


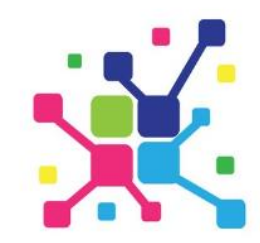

A J A D

Jurnal Pengabdian kepada Masyarakat

Vol. 1, No. 2, October, 2021, pp. 45-53 DOI : https://doi.org/10.35870/ajad.v1i2.12

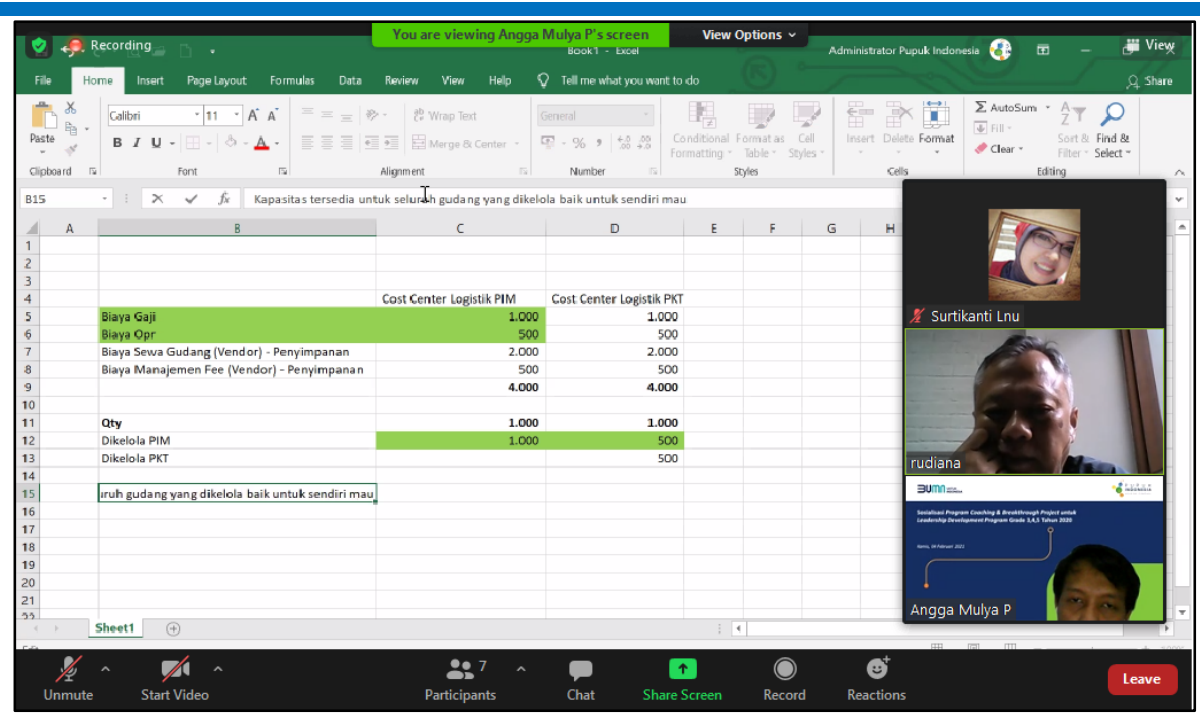

Gambar 1. Webinar diskusi dengan PT Pupuk Indonesia

\section{Format Alokasi Biaya dari Entitas Induk ke Entitas Anak}

Alokasi biaya dari Entitas Induk ke Entitas Anak, pada kompartemen biaya pemasaran dengan metode biaya langsung, tarif alokasi biaya menggunakan biaya tetap dan biaya variabel. Tarif biaya ini tergantung dari dasar alokasi biaya. Jika dasar alokasinya berlaku untuk 1 tahun berjalan dan akan ditetapkan setiap tahun, maka tarif alokasi biaya menggunakan tarif tetap, yang besar alokasi proporsionalnya dengan RKAP penjualan. Sedangkan dasar alokasi yang ditetap setiap periode mengikuti aktivitas entitas anak maka alokasi tarifnya menggunakan tarif variable, yang besar alokasi proporsional dengan nilai realisasi penjualan.

Tabel 3. Alokasi Biaya dengan Tarif Biaya Tetap

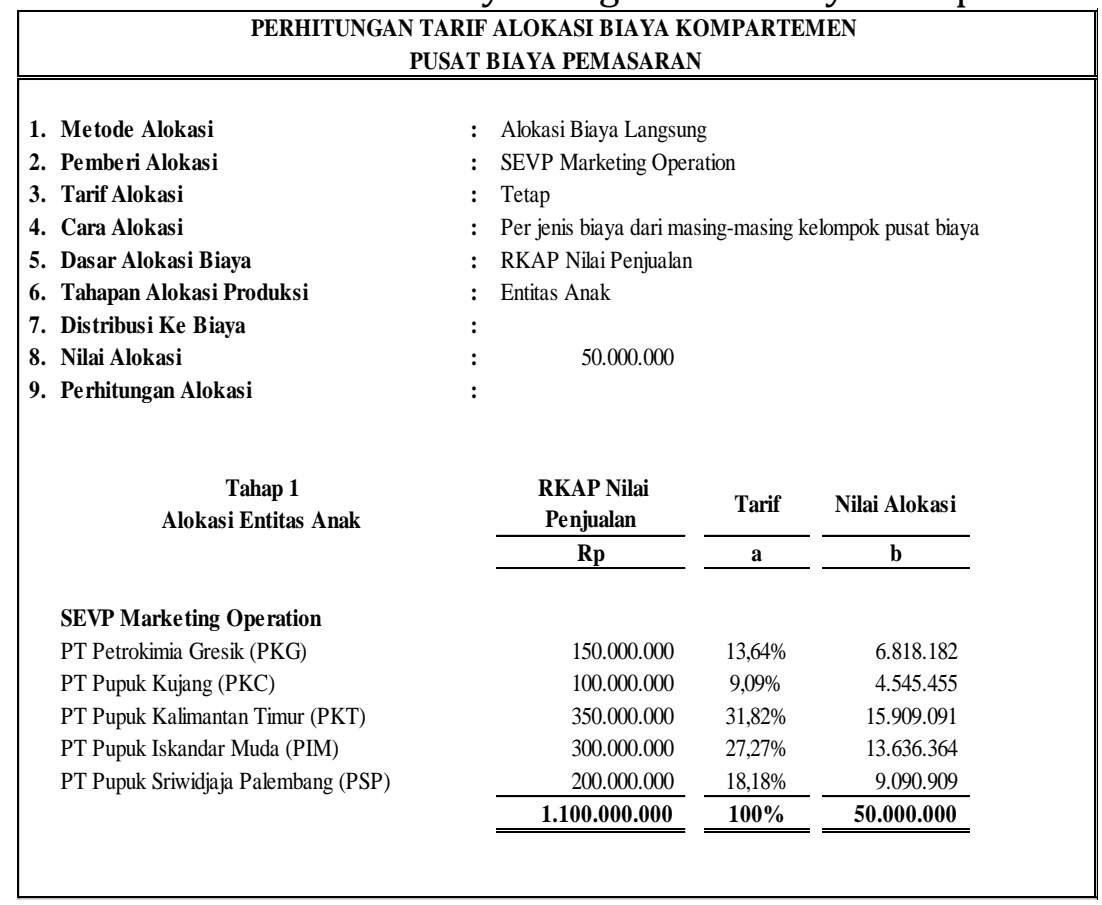


Dari tabel 3, dapat diketahui perhitungan tarif alokasi biaya kompartemen pusat biaya pemasaran, dengan metode alokasi biaya langsung menggunakan tarif alokasi tetap sedangkan dasar alokasi biaya menggunakan RKAP nilai penjualan. Sehingga dapat terlihat besaran alokasi biaya pemasaran untuk anak-anak perusahaan Pupuk Indonesia berbeda tergantung dari RKAP nilai penjualan masing-masing anak perusahaan.

Tabel 4. Alokasi Biaya Dengan Tarif Variabel

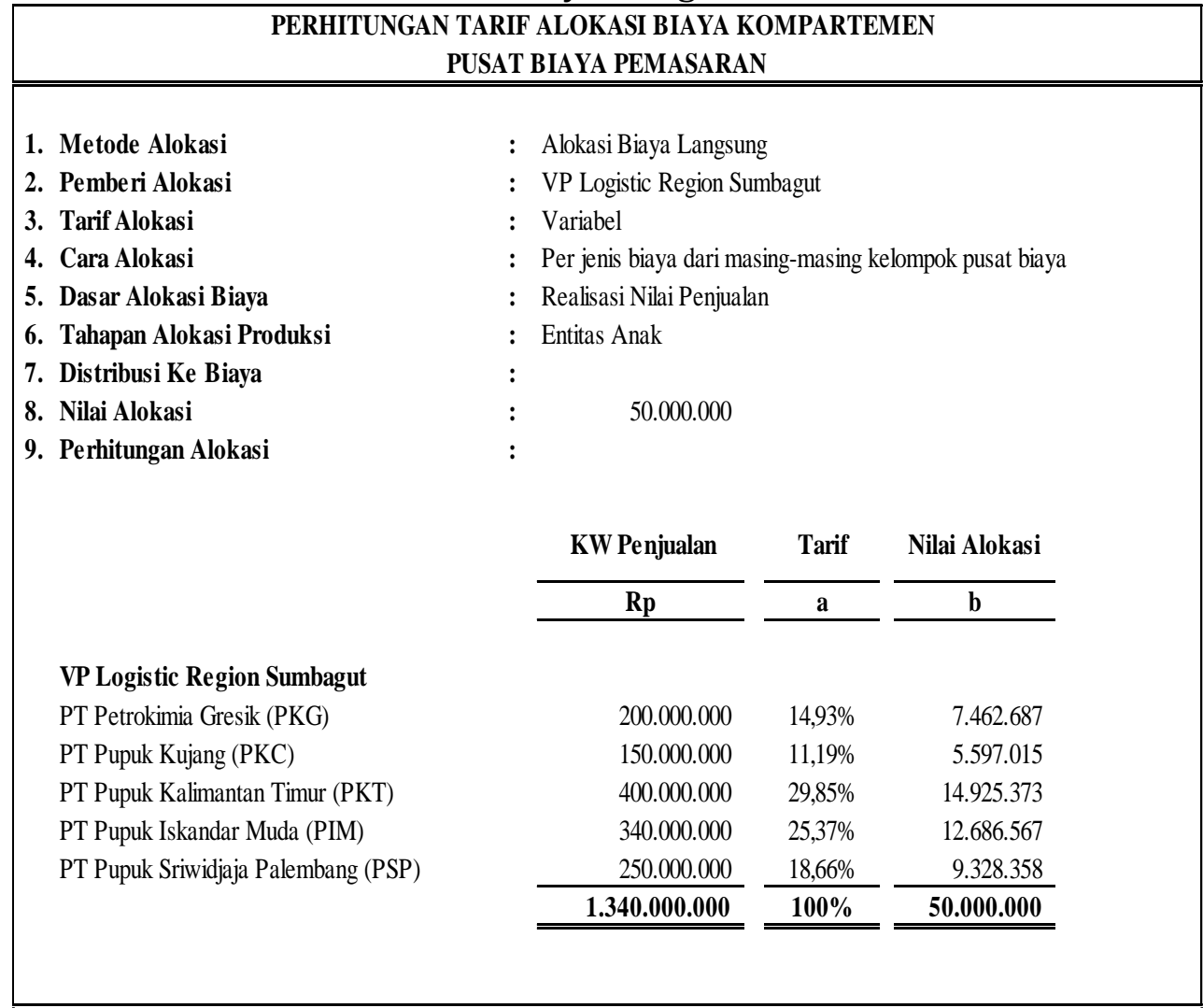

Dari tabel 4, dapat diketahui perhitungan tarif alokasi biaya kompartemen pusat biaya pemasaran, dengan metode alokasi biaya langsung menggunakan tarif alokasi variabel sedangkan dasar alokasi biaya menggunakan realisasi nilai penjualan. Sehingga dapat terlihat besaran alokasi biaya pemasaran untuk anak-anak perusahaan Pupuk Indonesia berbeda tergantung dari realisasi nilai penjualan masing-masing anak perusahaan.

\section{Kesimpulan}

Berdasarkan laporan kegiatan yang telah dipaparkan, berikut ini beberapa kesimpulan yang bisa dihasilkan.

1. Standar Tarif alokasi yang dihasilkan dapat digunakan sebagai dasar penentuan alokasi biaya yang wajar yang dikenakan kepada masing-masing anak perusahaan oleh induk perusahaan.

2. Perhitungan tarif alokasi biaya menggunakan metode biaya langsung. Penetapan tarif alokasi biaya ditentukan oleh dasar alokasi biayanya, bila dasar alokasinya berlaku 
untuk 1 tahun berjalan dan akan ditetapkan setiap tahun, maka tarif alokasi biaya menggunakan tarif tetap, yang besar alokasi proporsionalnya dengan RKAP penjualan.

Perhitungan tarif alokasi biaya menggunakan metode biaya langsung. Jika dasar alokasi yang ditetap setiap periode mengikuti aktivitas entitas anak maka alokasi tarifnya menggunakan tarif variable, yang besar alokasi proporsional dengan nilai realisasi penjualan.

\section{Daftar Referensi}

[1] Hansen, D.R, dan Mowen, MM. 2015. Management Accounting. Edisi 7. Jakarta: Salemba Empat.

[2] Kieso, D.E., J.J. Weygandt, dan T.D. Warfield. 2007. Intermediate Accounting. Twelfth Edition. John Wiley \& Sons, Inc. USA. Terjemahan E. Salim. 2008. Akuntansi Intermediate. Edisi Keduabelas. Jilid 2. Erlangga. Jakarta.

[3] Mulyadi. 2018. Akuntansi Manajemen. Jakarta. Salemba Empat

[4] Kompartemen Tata Kelola Korporasi PT Pupuk Indonesia (Persero). 2018. Pedoman Akuntansi PT Pupuk Indonesia (Persero). Penerapan Tata Kelola Perusahaan yang Baik (Code of Corporate Governance) di Lingkungan PT Pupuk Indonesia (Persero). 2017. Jakarta.

[5] Armanto, Witjaksono. 2006. Akuntansi Biaya. Edisi pertama. Yogyakarta. Penerbit: Graha Ilmu

[6] Hongren C.T, Srikant. M. Datar, Madhav V. Rajan. 2018. Cost Accounting: A Managerial Emphasis 18th Global Edition.

[7] Prastowo D, Dwi. (2015). Analisis Laporan Keuangan: Edisi Ketiga. Yoyakarta: Unit Penerbit Dan Percetakan Sekolah Tinggi Ilmu Manajemen YKPN.

[8] Iktan Akuntan Indonesia (IAI). 2020. Persediaan. Pernyataan Standar kuntansi Keuangan (PSAK) No. 14. DSAK-IAI. Jakarta.

[9] Ikatan Akuntan Indonesia (IAI). 2020. Assets Tetap Pernyataan Standar Akuntansi Keuangan (PSAK) No. 16. DSAK-IAI. Jakarta.

[10] Ikatan Akuntan Indonesia (IAI). 2020. Penyajian Laporan Keuangan. Pernyataan Standar Akuntansi Keuangan (PSAK) No. 1. DSAK-IAI. Jakarta. 